\title{
Variant Sternocleidomastoid with Extra Clavicular Head - A Case Report
}

\author{
Darshna Gulabrao Fulmali¹, Preeti Prabhakarrao Thute ${ }^{2}$, Harsha Atul Keche ${ }^{3}$, Vilas Keshvrao Chimurkar4 \\ 1,2,3,4 Department of Anatomy, Jawaharlal Nehru Medical College, Sawangi (Meghe), Wardha, Maharashtra, India.
}

\section{INTRODUCTION}

The sternocleidomastoid muscle is the key muscle that stretches obliquely across the neck, overlaps important structures, and divides the quadrangular area of neck into anterior and posterior triangular area. It arises by sternal and clavicular head. The sternal head arises from the anterior surface of the manubrium sterni and the clavicular head arises from the superior surface of the medial third of the clavicle. Sternal head is tendinous while clavicular is muscular. These two head are separated by a triangular gap which is called as the supra clavicular fossa. Depression on the skin surface over the supraclavicular fossa is an important land mark where jugular vein cannulation is usually performed. The clavicular head blends with the sternal head from its deeper aspect and the belly of the muscle get inserted over the external aspect of the mastoid process and the superior nuchal line in its lateral half. ${ }^{1}$

As stated by Bergman and Sanli, on the basis their attachment, the muscle has five parts namely the superficial sternomastoid, deep sternomastoid, sternooccipital, cleidomastoid, and cleido-occipital. ${ }^{2}$ Motor supply to the muscle is from the spinal part of accessory nerve and proprioceptive fibers from C2, C3 ventral rami. Sternocleidomastoid overlaps important structures in the neck like brachial plexus roots, cervical plexus, common carotid artery, accessory nerve.

We reported a unique case of variant sternocleidomastoid with extra clavicular head. The anaesthetist, surgeons, plastic surgeons, radiologists, radiotherapists should have knowledge about this type of variant of muscle during surgical procedures in neck as these can be used as myocutaneous flaps for reconstructive procedures. Physiotherapists should also have knowledge about the variant sternocleidomastoid muscle for treating cases like sternocleidomastoid syndrome. ${ }^{3}$

\section{PRESENTATION OF CASE}

During usual dissection of the head, neck and face region for the first year MBBS students in the Department of Anatomy, we observed variant origin of the sternocleidomastoid muscle in a male cadaver of about 70 years of age on left side of neck. In addition to the sternal and clavicular head of sternocleidomastoid, the sternocleidomastoid muscle of the left side had a third head which arises from the inner surface of the middle one-third of clavicle lateral to the clavicular head by tendinous origin and ascends as a flat sheet posterior and parallel to the clavicular head and joins with the other two heads to form the belly of the muscle for insertion over the lateral aspect of the mastoid process. The additional head overlaps the structure in the supraclavicular triangle \& occipital triangle. Structures like lesser occipital nerve, the trunk of the supraclavicular nerve, the accessory nerve that is normally in relation to the midpoint of the posterior border of the clavicular head were related to the midpoint of the posterior border of the additional head of the sternocleidomastoid muscle. The sternocleidomastoid muscle of the right side was normal.
Corresponding Author:

Dr. Darshna Gulabrao Fulmali, Aaditya Residency, Sarthak, Banglow No. 2, Sawangi (Meghe), Wardha - 442001, Maharashtra, India.

E-mail: bhotmagey2010@gmail.com

DOI: $10.14260 / j e m d s / 2020 / 715$

How to Cite This Article:

Fulmali DG, Thute PP, Keche HA, et al. Variant sternocleidomastoid with extra clavicular head - a case report. J Evolution Med Dent Sci 2020;9(43):3258-3260, DOI: 10.14260/jemds/2020/715

Submission 12-07-2020,

Peer Review 18-09-2020,

Acceptance 25-09-2020,

Published 26-10-2020.

Copyright (C) 2020 Darshna Gulabrao Fulmali et al. This is an open access article distributed under Creative Commons Attribution License [Attribution 4.0 International (CC BY 4.0)] 


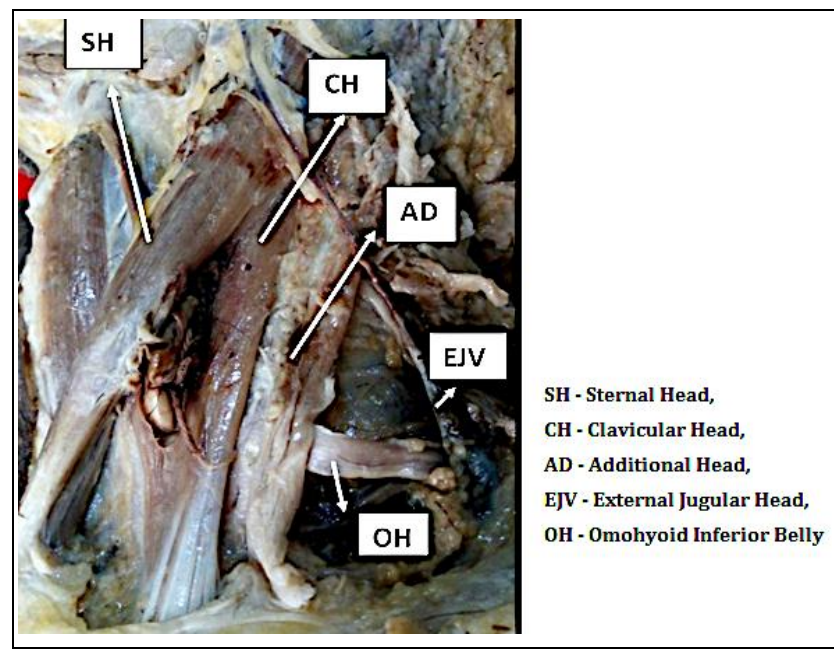

Figure 1. Variant Sternocleidomastoid with Extra Clavicular Head

\section{DISCUSSION}

Variant forms of sternocleidomastoid muscle have been reported by many authors. Variations of the sternocleidomastoid muscle at clavicular origin are more common than its sternal origin. ${ }^{4}$ The clavicular head could arises as single sheet of fibers as broad as $7.5 \mathrm{~cm}$ or divided into multiple slips of origin separated by small intervals. ${ }^{5}$

Hurtado (2016) reported bilateral variations in two $(12.5$ $\%$ ) cases they dissected. In the first case they found three clavicular head on one side and two clavicular head on another while in other case they found two clavicular head on both sides. ${ }^{6}$ Saha (2014) observed additional fibers in five $(27.8 \%)$ specimens, three had bilateral and two had unilateral variation. They found additional clavicular fibers joining with muscle bulk in four cases and completely separate additional clavicular head that runs parallel to the main sternocleidomastoid muscle in one specimen.7 Kaur (2012) reported a unique case having six heads of the muscle, two sternal, and four clavicular heads. Sternal heads were present side by side and out of four clavicular head two were superficial and two were deeper in position. ${ }^{8}$ Natsis K (2009) reported a case having five bilateral head of sternocleidomastoid two sternal and three clavicular. ${ }^{9}$ Kim (2014) reported a case with bilateral four muscle bellies of sternocleidomastoid, two sternomastoid, one cleido-occipital, and one cleido-mastoid occipital on one side and one sternomastoid, one cleido-occipital and two cleido-mastoids on another side. ${ }^{10}$

Our finding, unilateral additional clavicular head matches with the cases reported by researchers like Heo (2019), (Kaur 2017) Zeliha Fazliogullari (2010) Mehta V (2012) Cherian (2008) who found unilateral variation in the form of three heads of the muscle, one sternal head, and two clavicular head,11,12,13 but Rao TR (2007) found a bilateral additional slip of origin of the clavicular head of the sternocleidomastoid muscle. ${ }^{14}$

Variants of the sternal head have been reported by some authors like Nayak S R (2006) who reported additional sternal head of muscle arising from the manubrium sterni and the sternoclavicular joint. ${ }^{15}$ Boaro et al (2003) reported a newborn having four heads of sternocleidomastoid from sternum, clavicle, acromion process some fibres arising in between clavicle and acromion process. ${ }^{16}$

The sternocleidomastoid muscle develops in common with the trapezius muscle as a premuscle mass from last two occipital and upper cervical myotomes at the posterior sixth brachial arch that can be seen as an aggregation of cells (trapezius / SCM muscle complex) at Carnegie stage 15 and at CS17 the sternocleidomastoid and trapezius muscle may be viewed as separate muscle. During development of these myotomes any aberration in the signalling of Hox gene results into variant form of sternocleidomastoid muscle.17,18

Variant sternocleidomastoid with additional clavicular head in the present case may indicate abnormal mesodermal splitting in the posterior sixth brachial arch. This extra clavicular head may not be associated with difficulty in movement of the neck but it may interfere during any invasive procedure. ${ }^{14}$

The knowledge of the presence of additional heads of the sternocleidomastoid muscle is very helpful in clinical and surgical procedures. It is crucial for the anaesthetist \& surgeons to have knowledge about the variant form of the muscle, during internal jugular vein catheterization, myocutaneous cervical oesophagoplasty, suture line for carotid artery protection, while taking myocutaneous flap for facial defects, as a flap for superficial parotidectomy and many other head and neck surgeries. Radiologist, and radiotherapist should be aware of these types of variation during MR imaging observations of the neck region and while deciding the dose of botulinum for neck pain in patients receiving radiotherapy. ${ }^{7,8}$ It is also important for physiotherapists for treating cases of the sternocleidomastoid syndrome, torticollis, upper-crossed syndrome, neck-shoulder strain conditions, and functional limitation of neck flexion. ${ }^{3}$

Financial or other competing interests: None.

Disclosure forms provided by the authors are available with the full text of this article at jemds.com.

\section{REFERENCES}

[1] Standring S. Head and neck. In: Standring S, ed. Gray's anatomy: the anatomical basis of clinical practice. $40^{\text {th }}$ edn. London: Elsevier 2008:440-1.

[2] Bergman RA, Thompson SA, Afifi AK, et al. Muscles. In: Bergman RA, Thompson SA, Afifi AK, eds. Compendium of anatomic variation text, atlas, and world literature. Baltimore: Urban and Schwarzenberg 1988:32-3.

[3] Hasan T. Variations of the sternocleidomastoid muscle: a literature review. The Internet Journal of Human Anatomy 2011;2(1):1-6.

[4] Cherian SB, Nayak S. A rare case of unilateral third head of sternocleidomastoid muscle. Int $\mathrm{J}$ Morphol 2008;26(1):99-101.

[5] de Amorin AA, Lins CCSA, Cardoso APS, et al. Variation in clavicular origin of sternocleidomastoid muscle. Int J Morphol 2010;28(1):97-8.

[6] Hurtado DKA, Arquez HF. Bilateral supernumerary sternocleidomastoid heads with clinical and surgical implications. J Chem Pharm Res 2016;8(5):527-37. 
[7] Saha A, Mandal S, Chakraborty S, et al. Morphological study of the attachment of the sternocleidomastoid muscle. Singapore Med J 2014;55(1):45-7.

[8] Kaur A, Sharma A, Sharma M. A case of unusual unilateral accessory clavicular head of sternocleidomastoid muscle. North States Journal of Anatomy 2017;2(2):25-8.

[9] Natsis K, Asouchidou I, Vasileiou M, et al. A rare case of bilateral supernumerary heads of sternocleidomastoid muscle and its clinical impact. Folia Morphol (Warsz) 2009;68(1):52-4.

[10] Kim SY, Jang HB, Kim J, et al. Bilateral four heads of the sternocleidomastoid muscle. Surg Radiol Anat 2015;37(7):871-3.

[11] Heo YR, Kim JW, Lee JH. Variation of the sternocleidomastoid muscle: a case report of three heads and an accessory head. Surg Radiol Anat 2020;42(6):7113.

[12] Fazliogullari Z, Cicekcibasi AE, Dogan NU, et al. Músculo Elevador de la Clavícula y Tercera Cabeza Unilateral del Músculo Esternocleidomastoídeo: Reporte de Caso. Int J Morphol 2010;28(3):929-32.
[13] Mehta V, Arora J, Kumar A, et al. Bipartite clavicular attachment of the sternocleidomastoid muscle: a case report. Anat Cell Biol 2012;45(1):66-9.

[14] Ramesh RT, Vishnumaya G, Prakashchandra SK, et al. Variation in the origin of sternocleidomastoid muscle: a case report. Int J Morphol 2007;25(3):621-3.

[15] Nayak SR, Krishnamurthy A, SJ MK, et al. A rare case of bilateral sternocleidomastoid muscle variation. Morphologie 2006;90(291):203-4.

[16] Boaro SN, Neto F, Antonio R. Topographic variation of the sternocleidomastoid muscle in a just been born children. Int J Morphol 2003;21(4):261-4.

[17] Mekonen HK, Hikspoors JP, Mommen G, et al. Development of the epaxial muscles in the human embryo. Clin Anat 2016;29(8):1031-45.

[18] Dupont G, Iwanaga J, Lachkar S, et al. Bilateral sternocleidomastoid variant with six distinct insertions along the superior nuchal line. Anat Cell Biol 2018;51(4):305-8. 